This document is the Accepted Manuscript version of the following article: Haiwang Li, Haorann Huang, Guoqiang Xu, Jie Wen, and Hongwei Wu, 'Performance analysis of a compact air-air heat exchanger for aircraft gas turbine engine using LMTD method', Applied Thermal Engineering, Vol. 116, pp. 445-455, first published online 1 February 2017.

This manuscript version is made available under the CC-BY-NC-ND 4.0 license http://creativecommons.org/licenses/by-nc-nd/4.0/

The version of record is available online at doi:

http://dx.doi.org/10.1016/j.app/thermaleng.2017.01.003

(c) 2017 Elsevier Ltd. All rights reserved. 


\title{
Performance analysis of a novel compact air-air heat exchanger for aircraft gas turbine engine using LMTD method
}

\author{
Haiwang $\mathrm{Li}^{\mathrm{a}, \mathrm{b}, \mathrm{c}}$, Haoran Huang ${ }^{\mathrm{c}}$, Guoqiang $\mathrm{Xu}^{\mathrm{a}, \mathrm{b}}$, Jie Wen ${ }^{\mathrm{a}, \mathrm{b}}$, Hongwei Wu ${ }^{\mathrm{d}}$ \\ ${ }^{a}$ National Key Laboratory of Science and Technology on Aero Engines Aero-thermodynamics, \\ Beihang University, Beijing, 100191, China \\ ${ }^{b}$ The Collaborative Innovation Center for Advanced Aero-Engine of China, \\ Beihang University, Beijing, 100191, China \\ 'Aircraft/Engine Integrated System Safety Beijing Key Laboratory, \\ Beihang University, Beijing, 100191, China \\ ${ }^{\mathrm{d}}$ Department of Mechanical and Construction Engineering, Faculty of Engineering and \\ Environment, Northumbria University, Newcastle upon Tyne, NE1 8ST, United Kingdom
}

\begin{abstract}
In this article, a new compact cross-flow snake tube air-air heat exchanger is designed using logarithmic mean temperature difference method (LMTD) and its performance is experimentally investigated with optimized structure. This stainless-steel-made heat exchanger weighting $2.04 \mathrm{~kg}$ is able to cool the high temperature air from high pressure compressor in aero engine for more than $200 \mathrm{~K}$ (in certain cases) in a very limited space by using the coolant air from bypass duct. A comparison between calculated results and the obtained experimental data is presented and discussed. Results show that good agreement is achieved between the current calculations and experimental data. It also reveals that the present design method is proved to be relatively accurate in predicting the performance of the compact air-air heat exchanger for all the investigated structures. It is indicated that the new proposed air-air heat exchanger will have enhanced heat transfer capability with lower weight and higher compactness. In the current study, a new empirical correlation for the outside heat transfer coefficient of a six-pass snake tube heat exchanger is established using Wilson plot technique. The correlation will be very helpful for the researchers to design new air-air heat exchangers by showing where these are needed.
\end{abstract}

1. IntroductionThe inlet temperature of modern gas turbine engines has been increased to achieve higher thermal efficiency. Current turbine inlet temperatures are 
approaching $2000 \mathrm{~K}$, which is far beyond the allowable metal temperatures. As the material development of coatings and base material reach a culminating point, further increases in turbine inlet temperatures can only come from highly sophisticated cooling techniques [1]. Various cooling technologies including internal convective cooling and external film cooling have been successfully employed to cool high temperature components for the last half century. It is apparent that internal convective cooling is insufficient to maintain the blade at the required temperature and, thus, film cooling is required and becomes one of the most effective and widely used cooling methods to gas turbine blade to prevent thermal failure in extremely high temperature operations [3]. A comprehensive compilation of the available advanced cooling techniques used in the gas turbine industry has been encapsulated by Han et al.[4] in their book.

Though cooling is an effective way to enable higher inlet temperatures, an adequate cooling is challenging due to geometric constraints in combination with aerodynamic demands [5]. Besides, efficiency considerations demand effective cooling to be accomplished with minimum amount of cooling air which conflict with the application of film cooling that large cooling air are required. Since the coolant that facilitates the film cooling is extracted from the compressor, poor management of the cooling air can be otherwise detrimental to the engine overall efficiency. Furthermore, the cooling air capacity becomes more limited due to the increase in its stagnation temperature. Consequently, when both internal and external film cooling are inadequate, there is still an urgent demand to seek a new design concept or optimal cooling techniques for better and more efficient cooling systems.

A convenient source of additional cooling capacity is the kerosene fuel carried on board the aircraft. The best performing option is to utilize the fuel as the primary heat sink due to its high capacity so that compressor bleed air is cooled with fuel in a nearby fuel-air heat exchanger, and then used to cool the hot engine components [6]. The successful implementation of this application can lead to the coolant quality is greatly improved on one hand, and the desired nebulization for further efficient combustion on the other hand. However, as the fuel absorbs heat from the wall, the 
fuel temperature can be increased beyond its critical value. Due to aviation fuel is subject to high heat loads, it will lead to form unwanted surface/solid deposits, which can result in several effects that are detrimental to the aircraft fuel system and specifically in fuel nozzles[7]. Furthermore, the formation of coking will further reduce heat transfer by acting as an insulator on surfaces [9]. On the other hand, the fuel pressure is normally higher than the fuel critical pressure, thus, the fuel can become supercritical before injection into combustor [10]. Thus, the fuel thermodynamic and transport properties become very complex. As a consequence, the use of air-fuel heat exchanger only on the aero engine is restricted for its large size. A hybrid cooling system which consists of an air-air heat exchanger followed by an airfuel heat exchanger, however, could overcome those disadvantages, as shown in Fig. 1. The air bled from the high pressure compressor will be cooled initially through bypass air and then further cooled by the fuel. Since the air is cooled twice, the obtained cooling air can not only meet the cooling requirement of high heat-flux electronic components but also improve the combustion characteristics of the fuel

During literature surveys it was found that there were many research works investigated the air-side flow and heat transfer characteristics of finned tube and airair heat exchangers. Kong et al. [12] carried a three-dimensional investigation to clarify the air-side flow and heat transfer performances of flat and slotted finned tube bundles and validated against experimental data. Their results showed that the finned tube bundles with slotted fins are superior to those with flat fins in heat transfer performance, but present a high pressure drop. Liu et al. [13]performed a numerical study on the enhancement of air-side heat transfer performance by using perforated fins for a finned-tube heat exchangers (FHEXs) with large fin pitches. It was concluded that an optimal perforation design can be obtained to realize maximum increase in the $\mathrm{j}$ factor for the perforated FHEX compared with those of the plate FHEX without perforations. Vafajoo et al. [14] developed a two-dimensional, compressible and turbulent flow for flue gas-air Chevron type plate heat exchangers. Their study showed that the bigger angle of the Chevron type plates resulted in $18 \%$ enhancement in the output air temperature as well as an increase in the resulting flue 
gas pressure drop of $63 \%$ in comparison with the plate heat exchanger. Zhang [15] carried out a combined numerical and experimental study on the flow maldistribution and thermal performance deterioration in cross-flow air to air heat exchangers. Results showed that when the channel pitch is below $2.0 \mathrm{~mm}$, the flow distribution is quite homogeneous and the thermal deterimoration due to flow maldistribution can be neglected. Whereas when the channel pitch is larger than $2 \mathrm{~mm}$, the maldistribution is quite large and a 10-20\% thermal deterioration factor could be found. Vargas and Bejan [16] optimized the performance of air-air heat exchangers for airplane environmental control systems. Their results showed that the thermodynamic (constructed) optimization method of flow geometry illustrated in the paper is applicable to any systems that runs on the basis of a limited amount of fuel (exergy) installed onboard. Aristotle University of Thessaloniki and MTU Aero Engines also made many efforts on both experimental and numerical investigation of a new kind of air-air heat exchanger with U-shaped elliptic profiled tubes[17]. This heat exchanger allows the heat transfer between air from high pressure compressor and gas flow from turbine. By using oval tubes of staggered arrangement, the heat exchanger combines benefits from minimum aerodynamic pressure losses with high heat transfer effectiveness. Besides energy saving and effectiveness improvement, the heat exchanger can also reduce NOx emissions and noise levels, thanks to different combustion chamber conditions and to a high bypass ratio configuration.

Although many significant results on air-air heat exchanger have been already achieved by now, the application of air-air heat exchanger is still quite limited, especially for the cases in aero engine. As such, the present work aims to design and experimentally determine the performance of a compact air-air heat exchanger as well as acquire necessary data to provide support for the design of the cooling system.

\section{Nomenclature}
$\mathrm{A}_{\mathrm{o}}$
outside heat transfer area $\left(\mathrm{m}^{2}\right)$
$\mathrm{c}_{1}$
inlet section correction factor 


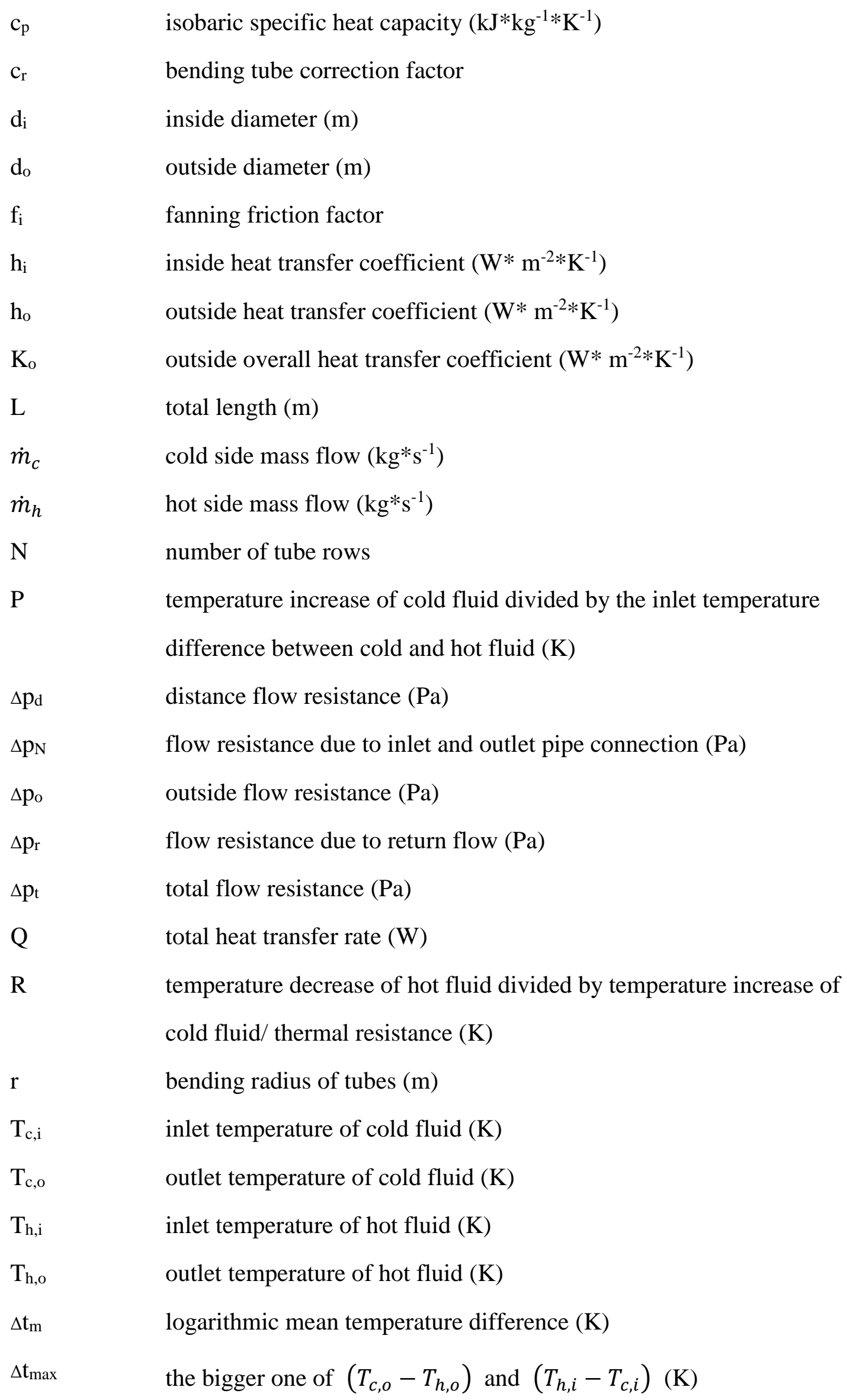




$\begin{array}{ll}\Delta \mathrm{t}_{\mathrm{min}} & \text { the smaller one of }\left(T_{c, o}-T_{h, o}\right) \text { and }\left(T_{h, i}-T_{c, i}\right)(\mathrm{K}) \\ \Delta \mathrm{t}_{\mathrm{m}, \text { counter }} & \text { logarithmic mean temperature difference when counter flow }(\mathrm{K}) \\ \mathrm{u}_{\mathrm{i}} & \text { inside flow velocity }\left(\mathrm{m}^{*} \mathrm{~s}^{-1}\right) \\ \mathrm{u}_{\mathrm{o}} & \text { outside flow velocity }\left(\mathrm{m}^{*} \mathrm{~s}^{-1}\right) \\ \mathrm{u}_{\mathrm{m}} & \text { average flow velocity }\left(\mathrm{m}^{*} \mathrm{~s}^{-1}\right) \\ \mathrm{Z}_{\mathrm{t}} & \text { number of tubes }\end{array}$

Dimensionless quantity

$\mathrm{Nu} \quad$ Nusselt number

Pr Prandtl number

Re Reynolds number

Abbreviation

CCA cooled cooling air

HPC high pressure compressor

LMTD logarithmic mean temperature difference method

Greek symbols

$\begin{array}{ll}\varphi & \text { temperature difference correction factor } \\ \lambda & \text { thermal conductivity }\left(\mathrm{W}^{*} \mathrm{~m}^{-1} * \mathrm{~K}^{-1}\right) \\ \rho & \text { density }\left(\mathrm{kg}^{*} \mathrm{~m}^{3}\right) \\ \mu & \text { dynamic viscosity }\left(\mathrm{Pa}^{*} \mathrm{~s}\right) \\ \phi & \text { correction factor of fluid viscosity }\end{array}$

Subscripts

$\mathrm{c}$

cold or cold side

$\exp \quad$ experimental

f fluid

h hot or hot side 


$\begin{array}{ll}\text { i } & \text { inside or inlet } \\ \text { o } & \text { outside or outlet } \\ \text { s } & \text { stainless steel/ fouling (thermal resistance) } \\ \text { t } & \text { total } \\ \text { ver } & \text { verification } \\ \text { W } & \text { wall }\end{array}$

\section{Design and verification methods}

\subsection{Design method}

In the current work, the Logarithmic Mean Temperature Difference Method (LMTD) is applied to design the proposed air-air heat exchanger. This method was introduced in detail by Kay and Nedderman [21] and will not be repeated here As it is usually the case, given the hot side inlet temperature $\left(T_{h, i}\right)$ and outlet temperature $\left(T_{h, o}\right)$, cold side inlet temperature $\left(T_{c, i}\right)$ and mass flow rates of hot side $\dot{m}_{h}$ and cold side $\left(\dot{m}_{c}\right)$, cold side outlet temperature $\left(T_{c, o}\right)$, then the total heat transfer rate $(Q)$ can be determined as follow:

$$
Q=\dot{m}_{h} c_{p_{h}}\left(T_{h, i}-T_{h, o}\right)=\dot{m}_{c} c_{p c}\left(T_{c, o}-T_{c, i}\right)
$$

where $c_{p}$ is the air isobaric specific heat capacity, which can be determined using EES $[22]$.

The logarithmic mean temperature difference for co-current flow and counter flow is defined as follow:

$\Delta t_{m}=\frac{\Delta t_{\max }-\Delta t_{\min }}{\ln \frac{\Delta t_{\max }}{\Delta t_{\min }}}$

where $\Delta t_{\text {max }}$ is the bigger one of $\left(T_{c, o}-T_{h, o}\right)$ and $\left(T_{h, i}-T_{c, i}\right)$, while $\Delta t_{\text {min }}$ is the smaller one. However, in most cases of the heat exchangers, fluid flow pattern is not simple co-current flow or counter flow, some complex flow patterns are found such as cross flow or mixed flow, the graph algorithms introduced by Underwood and Bowman are widely used [23] .That is, assuming the flow is counter flow and calculating $\Delta t_{m, \text { counter }}$, then the average temperature difference correction 
coefficient $\varphi$ can be found in graph using the following relations

$$
\varphi=f(P, R)
$$

where

$$
P=\frac{T_{c, o}-T_{c, i}}{T_{h, i}-T_{c, i}}
$$

and

$$
R=\frac{T_{h, i}-T_{h, o}}{T_{c, o}-T_{c, i}}
$$

The fixed logarithmic mean temperature difference are defined as follow

$$
\Delta t_{m}=\varphi * \Delta t_{m, \text { counter }}
$$

For circular tubes, if the structure and heat transfer area are assumed, the overall heat transfer coefficient based on outside tube $K_{0}$ can be calculated by

$\frac{1}{K_{o}}=\frac{1}{h_{i}} \frac{d_{0}}{d_{i}}+\frac{d_{0}}{2 \lambda_{s}} \ln \left(\frac{d_{o}}{d_{i}}\right)+\frac{1}{h_{o}}$

where,$h_{o}$ and $h_{i}$ are the outside and inside heat transfer coefficientare respectively,

defined as

$$
h_{o}=\frac{\lambda * N u_{o}}{d_{o}}
$$

and

$h_{i}=\frac{\lambda * N u_{i}}{d_{i}}$

The calculation of $N u$ is shown in Table 1. The heat transfer equation is defined

as

$Q=K_{o} A_{o} \Delta t_{m}$

Combining Eqs. (1), (4), (5) and (8), the heat transfer area $A_{0}$ can be calculated. Now the structure of the heat exchanger can be completely determined. In the following section, the flow resistance of both inside and outside, geometric dimensions and weight of the heat exchanger should be calculated. The structure should be optimized if the control parameters such as flow resistanceweight and volume do not satisfy the requirement.

\subsection{Verification method}

In this section, the heat transfer area is completely determined and the inlet temperatures on both hot side and cold side are given as well. The fluid temperature 
on either hot side or cold side is assumed initially, and the other side fluid temperature can be calculated by Eq. (1). Then $\Delta t_{m}, K_{o}$ and $Q$ can be determined using Eqs. (4), (5) and (8), respectively. Comparing the Q calculated by Eqs. (1) and (8), if the difference between these two Q is not small enough, the inlet temperature should be reassumed until the difference is acceptable, or the heat exchanger should be designed.

The inside flow resistance can be calculated as follow:

$\Delta p_{t}=\Delta p_{d}+\Delta p_{r}+\Delta p_{N}$

where $\Delta p_{t}$ is the total flow resistance, $\Delta p_{d}$ is the distance resistance, $\Delta p_{r}$ is the flow resistance due to return flow, and $\Delta p_{N}$ is the flow resistance due to inlet and outlet pipe connection.

With no baffle in heat exchanger, the calculation of outside flow resistance is similar to inside flow resistance.

Table 1 lists the relations or correlations for the calculation of the outside and inside heat transfer coefficients and flow resistances [24].

\section{Experimental apparatus and methods}

The experimental study was conducted on a new heat exchanger test rig at the National Key Laboratory of Science and Technology on Aero-engines Aerothermodynamics at Beihang University, China.

\subsection{Test rig}

The facility includes a high temperature air loop and a low temperature loop. These two loops provide high temperature air and low temperature air to simulate HPC bleed air (with high temperature) and bypass air (with low temperature) flow respectively. As shown in Fig. 2, the compressed air from air source is divided into two parts. In the high temperature air loop, the compressed air flows through a filter to remove impurities such as dusts. Then the air passes through flow control valve to control the flow rate with the desired value accurately by a thermal flow meter. The air stream is heated from room temperature to $220{ }^{\circ} \mathrm{C}$ by an electric heater with the accuracy of $\pm 1{ }^{\circ} \mathrm{C}$ to simulate hot air from HPC. Exiting the heater, the air enters a 
$4 \mathrm{~m}$ long straight tube to provide uniform inlet flow for the air-air heat exchanger. The test section including heat exchanger was depicted in Fig. 3. Similar to the high temperature air loop, low temperature air with room temperature flows through filter, flow control valve, flow meter and then enter the heat exchanger. The flow rate of low temperature air can be controlled using flow meter.

The back pressure of both loops was controlled by two different electromagnetic valve, respectively. The air in high temperature loop flows out the heat exchanger and then enters a water-cooled heat exchanger to reduce temperature. The air in low temperature loop from the heat exchanger is exhausted directly to atmosphere due to low temperature. What's more, in the experiments, the whole test section was covered by heat insulation materials with thermal conductivity of less than $0.012 \mathrm{~W} /\left(\mathrm{m}^{*} \mathrm{~K}\right)$ to reduce heat loss.

\subsection{Test section}

As illustrated in Error! Reference source not found., the air-air heat exchanger was designed carefully in order to reduce size and mass. The heat exchanger was fabricated from stainless steel type 321 and with size of $175 \mathrm{~mm}$ long, $145 \mathrm{~mm}$ wide and 140mm high, so it can be compacted enough to be installed into bypass of aero engine. Tubes with outer diameter of $5 \mathrm{~mm}$ and inner diameter of $4.4 \mathrm{~mm}$ were chosen, and each tube with length of $625.6 \mathrm{~mm}$ and six pass. The length, width and height of inlet and outlet headers are $135 \mathrm{~mm}, 32 \mathrm{~mm}$ and $32 \mathrm{~mm}$, respectively. The total weight of heat exchanger is $2.04 \mathrm{~kg}$. In all working condition, the outside pressure loss is less than $1.37 \%$, and the inside pressure loss is less than $2.49 \%$.

The detailed structure of the designed heat exchanger was shown in Fig. 5.

Fig. 5(a) shows the detailed dimensions of tube. Limited by material and diameter of tubes, tube bending radius should larger than $6 \mathrm{~mm}$, which leads to a big distance between adjacent tubes. In order to make the heat exchanger more compact, four tubes are arranged in parallel. As shown in Fig. 5(b), four tubes are arranged in a row, and with 10 rows in total. It is worth to mention that, in order to avoid interference between the tubes, four adjacent tubes are bended in opposite directions 
after exceeding the red line. The bended angle between the tube and the gravity line is $8^{\circ}$. In this way all the straight section can be arranged in the same level. Using this arrangement, the heat exchanger can be more compact, and heat transfer area in unit volume can be increased to the maximum extent. In addition, it is benefit to calculate flow resistance and heat transfer ability of heat exchanger.

All 40 tubes were fabricated and arranged firstly. After that, two groups of support plate were installed into the interspace between tubes to approve the firmness of tubes. At the same time, the inlet and outlet section of tubes were inserted into headers together. Then liquid solder was coated on the contact surfaces between support plates as well as headers and tubes. At last, the whole heat exchanger was sent to a high temperature vacuum braze furnace, in which the heat exchanger was brazed. Fig. 5(c) shows the photos of completed heat exchanger.

\subsection{Measurement accuracy}

In each loop, pressures are measured by an absolute and a differential Rosemount pressure transmitter, with accuracies of $0.25 \%$ and $0.04 \%$ of the full-scale reading, respectively. The transmitters are used to record absolute pressure and pressure drop across the heat exchanger for both high temperature side and low temperature side, respectively.

The air flow rates of high temperature side and low temperature side are measured by a thermal flow meter and an orifice flow meter, respectively. These flow meters possess an accuracy of $\pm 0.5 \%$ of reading with maximum ranges of $0-0.4 \mathrm{~kg} / \mathrm{s}$ and $0-1.5 \mathrm{~kg} / \mathrm{s}$, respectively.

Type K sheathed thermocouples were used throughout the facilities with an accuracy of $\pm 0.6 \mathrm{~K}$. Temperatures were measured at upstream and downstream of both high and low temperature side in the heat exchanger.

All experimental measurement data were collected by ADAM 4018, recorded by ADAM 4520 and then recorded in a computer system so these the data can be processed and stored easily.

\subsection{Uncertainty analysis}

Based on Eqs. (1) and (2), by using the error propagation under non-linear form 
[25], the uncertainty of the heat transfer rate and logarithmic mean temperature

difference can be calculated using following equations:

$$
\begin{gathered}
\frac{\Delta\left(\Delta T_{\max }\right)}{\Delta T_{\max }}=\sqrt{\frac{\left(\Delta T_{h, \text { in }}\right)^{2}+\left(\Delta T_{c, \text { in }}\right)^{2}}{\left(T_{h, \text { in }}-T_{c, \text { in }}\right)^{2}}} \\
\frac{\Delta\left(\Delta T_{\min }\right)}{\Delta T_{\min }}=\sqrt{\frac{\left(\Delta T_{h, \text { out }}\right)^{2}+\left(\Delta T_{c, \text { out }}\right)^{2}}{\left(T_{h, \text { out }}-T_{c, \text { out }}\right)^{2}}}
\end{gathered}
$$

and

$$
\begin{gathered}
\frac{\Delta Q}{Q}=\sqrt{\left(\frac{\Delta m}{m}\right)^{2}+\frac{\Delta T_{\text {in }}{ }^{2}+\Delta T_{\text {out }}{ }^{2}}{\left(T_{\text {in }}-T_{\text {out }}\right)^{2}}}=6.4 \% \\
\frac{\Delta\left(\Delta T_{m}\right)}{\Delta T_{m}}=\frac{\sqrt{\left(\frac{\partial \Delta T_{m}}{\partial \Delta T_{\max }} \Delta\left(\Delta T_{\text {max }}\right)\right)^{2}+\left(\frac{\partial \Delta T_{m}}{\partial \Delta T_{\text {min }}} \Delta\left(\Delta T_{\text {min }}\right)\right)^{2}}}{\Delta T_{m}}=1.94 \%
\end{gathered}
$$

The equation of the uncertainty of heat transfer coefficient as follow:

$$
\frac{\Delta K}{K}=\sqrt{\left(\frac{\Delta Q}{Q}\right)^{2}+\left(\frac{\Delta\left(\Delta T_{m}\right)}{\Delta T_{m}}\right)^{2}}
$$

Taking the individual uncertainties of the measurements into Eqs. (14), the combined uncertainty is estimated to be $6.69 \%$ in all experimental regions.

\section{Results and discussion}

As discussed earlier in this paper, room temperature air and heated air were used to simulate bypass air and HPC bleed air in an aircraft engine, respectively.

Experiments were performed to test the overall flow resistance and heat transfer of the heat exchanger. In the experiments, the temperature and flow rates for high temperature air and low temperature air various respectively. In addition, repeatability tests are made to investigate the effect of heat exchanger processing

\subsection{Flow resistance}

Fig. 6 shows the pressure loss in hot side and cold side of heat exchanger with various mass flow rates. From the figure we can learned that the cold side flow resistance is very low, and the hot side is much higher. However, the maximum of hot side mass flow is less than $0.075 \mathrm{~kg} / \mathrm{s}$, as the result, the pressure loss is less than $25 \%$.

Fig. 7 presents the divergence between predicting pressure loss and experimental 
results for hot air side and cold air side, respectively, with six different mass flow. For the hot air side, the percent pressure loss error is defined as:

$$
\text { Hot side pressure loss error }=\frac{\left|\Delta p_{h, \text { exp }}-\Delta p_{h, v e r}\right|}{\Delta p_{h, v e r}} * 100 \%
$$

where $\Delta p_{h, \text { exp }}$ and $\Delta p_{h, v e r}$ are the measured pressure loss and the predicted pressure loss, respectively. Similarly, the percent pressure loss error for the cold side is defined as:

$$
\text { Cold side pressure loss error }=\frac{\left|\Delta p_{c, \text { exp }}-\Delta p_{c, v e r}\right|}{\Delta p_{c, v e r}} * 100 \%
$$

where $\Delta p_{c, \text { exp }}$ and $\Delta p_{c, v e r}$ are the measured pressure loss and the predicted pressure loss, respectively. Fig. 7(a) shows that the error for hot air side are lower than $15 \%$ for all seven mass flow rates. These error may be related to the uncertainties associated with the several instruments such as flow meters and sheathed thermocouples. Meanwhile, the air flow rates cannot be recorded very accuracy due to fluctuations even if the flow rates of both side are the averaged value by time. Fig. 7(b) shows that the maximum difference between predicted value and experimental value is about $30 \%$ for different mass flow rates. Besides the reasons already mentioned for hot air side, the big error is also related to the very small pressure drop of cold side because that the relative error by Rosemount pressure transmitter in experiments is larger. Nevertheless, the error value in Fig. 7 still support the overall accuracy of heat exchanger design and verification method.

\subsection{Heat transfer}

The heat transfer rates of heat exchanger are measured and calculated for the cold and hot side, respectively, as

$$
Q_{h}=\dot{m}_{h} c_{p h}\left(T_{h, \text { in }}-T_{h, \text { out }}\right)
$$

and

$$
Q_{c}=\dot{m}_{c} c_{p c}\left(T_{c, \text { out }}-T_{c, \text { in }}\right)
$$

The overall heat transfer rates are also experimentally measured and calculated by Eqs. (8).

In these experiments, the hot side flow rates range from $0.05 \mathrm{~kg} / \mathrm{s}$ to $0.2 \mathrm{~kg} / \mathrm{s}$ and 
the cold side from $0.1 \mathrm{~kg} / \mathrm{s}$ to $0.6 \mathrm{~kg} / \mathrm{s}$. As illustrated in Fig. 8, predicted and experimental heat transfer rates were calculated and compared with each other for hot side and cold side respectively. At the same time, the cold air flow rate is $0.4 \mathrm{~kg} / \mathrm{s}$ according to Eqs. (17), (18) and (8), respectively. Fig. 9 compared the same comments with Fig. 8 in the hot air flow rate of $0.1 \mathrm{~kg} / \mathrm{s}$. In both trend and magnitude, the results show good agreement in a wide range of mass flow rates for both hot side and cold side.

The all 30 calculated and experimental heat transfer rates were compared in Fig. 10. The deviation between experimental average heat transfer rate and calculated values for the cold air side, hot air side and overall heat exchanger is $3.06 \%, 2.04 \%$ and $2.10 \%$, respectively. What's more, when predicting hot air side heat transfer rates, $86.7 \%$ points in 30 points are in the $5 \%$ error band, and when predicting cold air side and overall heat transfer rates, the proportion is even higher, which is up to $96.7 \%$ in 30 points in $5 \%$ error band.

These results demonstrated that the design method in this paper as a tool for heat transfer performance prediction of compact air-air heat exchangers is effective. .

\section{Repeatability}

Considering the effect of machining error, repeatability test were conducted in the paper. Two air-air heat exchanger with same scale and other parameters were manufactured and tested under the hot side flow rate of $0.08 \mathrm{~kg} / \mathrm{s}$ and $0.1 \mathrm{~kg} / \mathrm{s}$ and cold side from $0.2 \mathrm{~kg} / \mathrm{s}$ to $0.4 \mathrm{~kg} / \mathrm{s}$, respectively. Fig. 11 exhibited the divergence in heat transfer rate prediction with six different working conditions. The results showed that the influence of machining on heat transfer rates is less than $10.8 \%$, which is acceptable in engineering practice.

\section{Outside Heat Transfer Coefficient Empirical Relationship}

In heat exchanger design, the determination of outside heat transfer coefficient empirical relationship is one of the most important issues. However, no empirical relationship can be used in all cases. For instance, the heat transfer coefficient empirical relationship used in this paper is Zhukauskas empirical relationship. But the Zhukauskas empirical relationship is developed for the condition of fluid flowing 
across straight tube row. It is not suitable for the snake tubes which was applied in this paper because snake tubes have some bent section. This means that the Zhukauskas relationship cannot explain the heat transfer pattern of the snake tube appropriately. On the other hand, the structure and geometry are always changed with different condition in application, so it is important to develop an empirical relationship for the snake tube heat exchanger.

Because the heat exchanger applied in aero engine is compact, it is hard to measure wall temperature of tubes. As the consequence, it is difficult to calculate heat transfer coefficient between wall and outside air also. The so-called Wilson plot technique was introduced to determine the heat transfer relationships for either side of a heat exchanger based on measurements of heat transfer rate and overall temperature difference between the two fluids. This avoids the difficult task to measure the wall temperature along flow direction

By using Wilson plot technique, the form of relationship should be determined first. Reference to Zhukauskas relationship, the relationship of heat exchanger can be defined as:

$$
N u=C \operatorname{Re}^{n} \operatorname{Pr}^{m}\left(\frac{P r_{f}}{P r_{w}}\right)^{0.25}
$$

where $m$ can be determined as 0.36 with the Re number range from 1 to 2000000 . In the following discussion, the values of $C$ and $n$ in the relationship will be determined.

In heat transfer process, the total thermal resistance is defined as follow:

$$
R_{t}=\frac{1}{K}=\frac{d}{\lambda * N u}=R_{w}+R_{i}+R_{o}+R_{s}
$$

where $R_{w}$ is thermal resistance of tube wall, $R_{i}$ is inside thermal resistance, $R_{o}$ is outside thermal resistance, $R_{S}$ is fouling thermal resistance. Replace $R_{O}$ with $\frac{d}{\lambda * N u}$, $R_{t}$ is as follow:

$$
R_{t}=R_{w}+R_{i}+R_{s}+\frac{1}{\mathrm{C} \frac{\lambda}{d} \operatorname{Pr} m\left(\frac{P r_{f}}{P r_{w}}\right)^{0.25}}\left(R e^{-n}\right)
$$

Eqs. (22) can be deformed as:

$$
\mathrm{Y}=\mathrm{a}+\mathrm{b} * \mathrm{X}
$$


where $Y=R_{t}, X=R e^{-n}, a=R_{w}+R_{i}+R_{s}, b=\frac{1}{\mathrm{C} \frac{\lambda}{d} \operatorname{Pr} m\left(\frac{P r_{f}}{P r_{w}}\right)^{0.25}}$.

All coefficient in $b$ is constant, so $b$ is considered as a fixed value. In some experimental conditions, $N u$ for the inside of tube is kept constant, so $R_{i}$ and $R_{w}$ can be considered as fixed values also. Because the heat exchanger is newly fabricated, the fouling thermal resistance $R_{S}$ can be considered as zero. As the consequence, the coefficient $a$ can be considered as a fixed value also. According the above discussion, Eqs. (23) reduces into a linear equation. In this equation, $a$ is intercept and $b$ is slope.

In the experiments, when the value of $R e$ and corresponding value of $N u$ is recorded, the relationship between $\mathrm{X}$ and $\mathrm{Y}$ can be described in figures, e.g. Fig.12. The relationship between $\mathrm{X}$ and $\mathrm{Y}$ can be obtained by fitting the data for $\mathrm{X}$ and $\mathrm{Y}$. And then, the values of $C$ and $n$ can be determined according the definition.

Fig. 12 exhibits the line fitted by using Wilson plot technique.

The modified outside heat transfer coefficient empirical relationship for six-pass snake tube heat exchanger is shown as follow:

$$
N u=0.62 \operatorname{Re}^{0.4748} \operatorname{Pr}^{0.36}\left(\frac{P r}{P r_{w}}\right)^{0.25}
$$

valid for $0.6<\operatorname{Pr}<1$ and $1000<\operatorname{Re}<15000$.

The empirical relationship can be a reference for the design of heat exchanger with similar structure.

There are three requirements should be satisfied when using Wilson plot technique. Firstly, the unknown coefficient should be no more than two; secondly, the fouling thermal resistance should be unchanged during the experiment; thirdly, the inside heat transfer coefficient should be unchanged. All the three conditions were all satisfied in the experiments.

\section{Conclusions}

This paper mainly investigated the design, verification and performance assessment of a novel air-air heat exchanger intended for potential application in gas turbine engines. The logarithmic mean temperature difference method (LMTD) is used in heat exchanger design and verification. The comparison between the 
calculated results and experimental data was carried out. Analysis of the experimental and theoretical results may lead to the following main conclusions:

(1) A new type of compact cross-flow snake tube heat exchanger was designed and optimized.

(2) Comparisons between calculation and experiment show good agreement in both pressure losses and heat transfer rates. Repeatability experiments are made as well. All these proves the design method is a reliable tool for predicting the heat exchanger performance under actual aircraft engine working condition and for the design of different sized snake tube heat exchanger.

(3) Wilson plot technique is used in modifying outside heat transfer coefficient empirical relationship, and an empirical relationship for outside heat transfer of six-pass snake tube heat exchanger is developed, which can be a reference for the design of heat exchanger with similar structure. 


\section{References}

[1] Kim, Y.J., Kim, S.M., 2004. Influence of shaped injection holes on turbine blade leading edge film cooling. International Journal of Heat and Mass Transfer 47, 245-256.

[2] Garg, V.K., 2001. Modeling film-coolant flow characteristics at the exit of shower-head holes. International Journal of Heat and Fluid Flow 22, 134-142.

[3] Yuen, C.H.N., Martinez-Botas, R.F., 2003. Film cooling characteristics of a single round hole at various streamwise angles in a crossflow: Part I effectiveness. International Journal of Heat and Mass Transfer 46, 221-235.

[4] Han, J.C., Dutta, S., Ekkad, S.V., Gas Turbine Heat Transfer and Cooling Technology. Taylor $\&$ Francis, New York, 2000,

[5] Martini, P., Schulz, A., Bauer, H.J., 2006. Film cooling effectiveness and heat transfer on the trailing edge cutback of gas turbine airfoils with various internal cooling designs. Journal of Turbomachinery, Transactions of the ASME 128, 196-205.

[6] Huang, H., Spadaccini, L.J., Sobel, D.R., 2004, Fuel-Cooled Thermal Management for Advanced Aeroengines, Transactions of the ASME. 126, 284-293.

[7] Altin, O., Eser, S., 2001a. Analysis of carboneceous deposits from thermal stressing of a JP-8 fuel on superalloy foils in a flow reactor. Industrial \& Engineering Chemistry Research 40(2), 589-595.

[8] Altin, O., Eser, S., 2001b. Analysis of solid deposits from thermal stressing of a JP-8 fuel on different tube surfaces in a flow reactor. Industrial \& Engineering Chemistry Research40(2), 596-603.

[9] Linne, D.L., Meyer, M.L., Edwards, T., Eitman, D.A., Evaluation of heat transfer and thermal stability of supercritical JP-7 fuel. NASA Technical Memorandum 107485, AIAA-97-3041.

[10] Gao, W., Liang, H.S., Xu, Q.H., Lin, Y.Z., Sung, C.J., Injection of supercritical aviation kerosene fuel into quiescent atmospheric environment. 45thAIAA/ASME/SAE/ASEE Joint Propulsion Conference \& Exhibit, 2-5 August 2009, Denver, Colorado, AIAA 2009-4927.

[11] Zhong, F.Q., Fan, X.J., Yu, G., Li, J.G., Sung, C.J., 2009. Heat transfer of aviation kerosene at supercritical conditions. Journal of Thermophysics and Heat Transfer 23(3), 543-550.

[12] Kong, Y. Q., Yang, L. J., Du, X. Z., \& Yang, Y. P., 2016. Air-side flow and heat transfer characteristics of flat and slotted finned tube bundles with various tube pitches. International Journal of Heat and Mass Transfer, 99, 357-371.

[13] Liu, X., Yu, J., \& Yan, G., 2016. A numerical study on the air-side heat transfer of perforated finned-tube heat exchangers with large fin pitches. International Journal of Heat and Mass Transfer, 100, 199-207.

[14] Vafajoo, L., Moradifar, K., Hosseini, S. M., \& Salman, B. H., 2016. Mathematical modelling of turbulent flow for flue gas-air Chevron type plate heat exchangers. International Journal of Heat and Mass Transfer, 97, 596-602.

[15] Zhang, L. Z., 2009. Flow maldistribution and thermal performance deterioration in a crossflow air to air heat exchanger with plate-fin cores. International journal of heat and mass transfer, 52(19), 4500-4509.

[16] Vargas, J. V., \& Bejan, A., 2001. Thermodynamic optimization of finned crossflow heat exchangers for aircraft environmental control systems. International Journal of Heat and Fluid Flow, 22(6), 657-665. 
[17] Boggia, S., \& Rud, K., 2005. Intercooled recuperated gas turbine engine concept. AIAA Paper, (2005-4192).

[18] Missirlis, D., Yakinthos, K., Palikaras, A., Katheder, K., \& Goulas, A., 2005. Experimental and numerical investigation of the flow field through a heat exchanger for aero-engine applications. International Journal of Heat and Fluid Flow, 26(3), 440-458.1

[19] Yakinthos, K., Missirlis, D., Palikaras, A., Storm, P., Simon, B., \& Goulas, A., 2007. Optimization of the design of recuperative heat exchangers in the exhaust nozzle of an aero engine. Applied Mathematical Modelling, 31(11), 2524-2541.

[20] Albanakis, C., Yakinthos, K., Kritikos, K., Missirlis, D., Goulas, A., \& Storm, P., 2009. The effect of heat transfer on the pressure drop through a heat exchanger for aero engine applications. Applied Thermal Engineering, 29(4), 634-644.

[21] Kay, J. M., \& Nedderman, R. M., 1985. Fluid mechanics and transfer processes. CUP Archive.

[22] S.A. Klein, Engineering Equation Solver (EES), F-Chart Software, Madison, WI.

[23] MeiZhong Shi, ZhongZheng Wang, Principle and design of heat exchangers, fifth ed., Southeast University Press, Nanjing, China, 1989 (in Chinese)

[24] ShiMing Yang, WenQuan Tao, Heat transfer, fourth ed., Higher Education Press, Beijing, China, 1998 (in Chinese)

[25] Ku, H. H., 1966. Notes on the use of propagation of error formulas. Journal of Research of the National Bureau of Standards, 70(4). 